\title{
Art Walk / \\ Bridging Urban Spaces
}

REFLECTIVE PRACTICE

\section{Heather Woofter, Sung Ho Kim}

\begin{abstract}
The Art Walk project is a stitched landscape that joins several art and media institutions in Grand Center, St. Louis. The current condition of Grand Center allows few moments of connectivity and sense of continuity between urban spaces. The project is divided into four multi-cultured zones that are currently separated by parking lots, pedestrian inaccessible easements, and gated buildings. The urban strategies are part architecture, art, and industrial design elements. They interface with landscape planning to engage the public in multiple scales of activity in order to bridge between discreet urban spaces.
\end{abstract}

Keywords: Art Walk, Grand Center, Axi:Ome, urbanism, landscape

The Art Walk project is a stitched landscape that joins several art and media institutions in the Grand Center area of St. Louis. The current condition of Grand Center allows few moments of connectivity and sense of continuity between the urban spaces.

Many American cities face these challenges that evolved, in part, by the predominance of an automotive culture weaving access points and thoroughfares through historically large blocks of public space. In addition, the purposeful labyrinthine management of traffic flows supported a purposeful effort to create defensible enclaves of space around like-minded Institutions. This gating of public space contradicts contemporary thinking, lessening the richness of cross-cultural exchanges and more environmentally 
sensitive maneuvers through the city. The resultant predominance of the parking lot also creates division, by privileging a population with cars and by creating asphalt islands in-between visitor destinations. Over time these gaps in the urban fabric provide unique opportunities for landscapes within the city that are moments of public assembly and relief from the density of built form.

\section{CONNECTIVITY THROUGH ART}

The project addresses the fundamental question of "what is art" by establishing the position that art surrounds us in every day life - from social exchanges, to historic building facades, to the phenomena found in our natural environment. This position favors the experience of a connective walk, rather than the dominance of singular objects positioned along a path. By viewing art as a form of communication, the media institutions adjacent to museums provide opportunity for various forms of expression that are "in the moment."

In this way, the dialogue between curated events and an open discussion restores the idea of the city as primarily a social space, representative of plural populations, unique artifacts and stories. Framing these events, the notable building facades provide a visually rich backdrop referencing the cultural ambitions of historic philanthropic efforts to provide access to educational resources. Walking between them is akin to an exterior gallery experience, with the ceiling as sky and the gallery rooms emerging from the urban context.

With this analogy in mind, the streetscape of Grand Center, which primarily assumed a utilitarian role, needed to shift its definition from one burdened with connotations of abandoned space to a cultural public right-of-way. As part of the gallery experience, the walk was designed to evoke a heightened sense of the site (subtle sounds of the wind, presence of the sky, partial views of facades, sense of topography and seasonal changes) in order to encourage pedestrians to be observers and interface with the uniqueness of each urban room.

\section{URBAN CHARACTERS AND ROOMS}

"Urban rooms" are defined as landscape spaces that create distinct territories between existing buildings held within shared public and private zones of streets, parking lots and gardens. These rooms frame the pedestrian flows, legible from above as a dispersal of vector patterns strengthening the connections between institutions, rather than a single flow along a pathway. As each space has unique properties of movement along and through its boundaries, sensors pick up these fluctuations and activate a series of multimedia, sensory and visual effects to metaphorically turn on the lights as one enters the room.

At a smaller scale, several places within Art Walk contain "urban characters," such as telescopes, wind devices, light elements, and rainwater collectors: 
devices that interface with the urban context. These characters are part architecture, art, and industrial design elements. They interface with landscape strategies to engage the public in reading subtle changes to the environment, and recognize dispersed connections within the city. Primarily, we desire to turn parts of the city to interior rooms, working with the existing fabric to frame gateways and thresholds, with minimal intervention performed by the connectors.

\section{INDIGENOUS AND FOREIGN LANDSCAPES}

In recognizing that the limited green spaces in Grand Center are maintained through less sustainable practices, this project seeks to promote a robust environment of indigenous plantings that establish a fluid landscape with competitive growth among plants and a variegated ecology. Dispersed among these natural plantings are "islands" of more manicured elements, referred to as floating gardens. These mounds create an artificial ground, change the horizon, provide a place of rest, and soften the horizontality of the continuous ground-scape. They stand out as unusual elements, thus signaling a portal into passageways and working to hold the necklace of spaces together as part of a larger system.

The parking lot territories present unique challenges to the landscape. On one side, the number of institutional events justifies maintaining the lots, and in contrast, the community desires an integrated design approach that transforms surface lots into sensitive components of exterior space. If one looks at the transformation of the urban space over time, these lots could naturally "decay" into landscapes through a select series of cuts and disruptions. As a first act, we considered the large lot adjacent to the lowest elevation of the district to primarily address the issue of rainwater collection. A series of cut channels collect water, run through street landscape elements, with a final dispersal at the rainwater retention site. In the context of the city grid geometry, the landscape provides relief, a new geometry and transitional material, transformative and invading the static street.

\section{FINAL REMARKS}

The Art Walk project aspires to activate and transform an urban space over time through the complexity of competing interests and changing infrastructures. At one impetus, seven private owners and local government came together to reimagine their connective property. Their conversations and agreements will shift, the specific details of the architecture will modify, but the relationships between them will never be the same for a moment of shared vision. Combine this with citizens appropriating spaces, claiming joint interest in their city to create transformative relationships; the project's realization is found somewhere in this momentum of reimagining urbanity. 

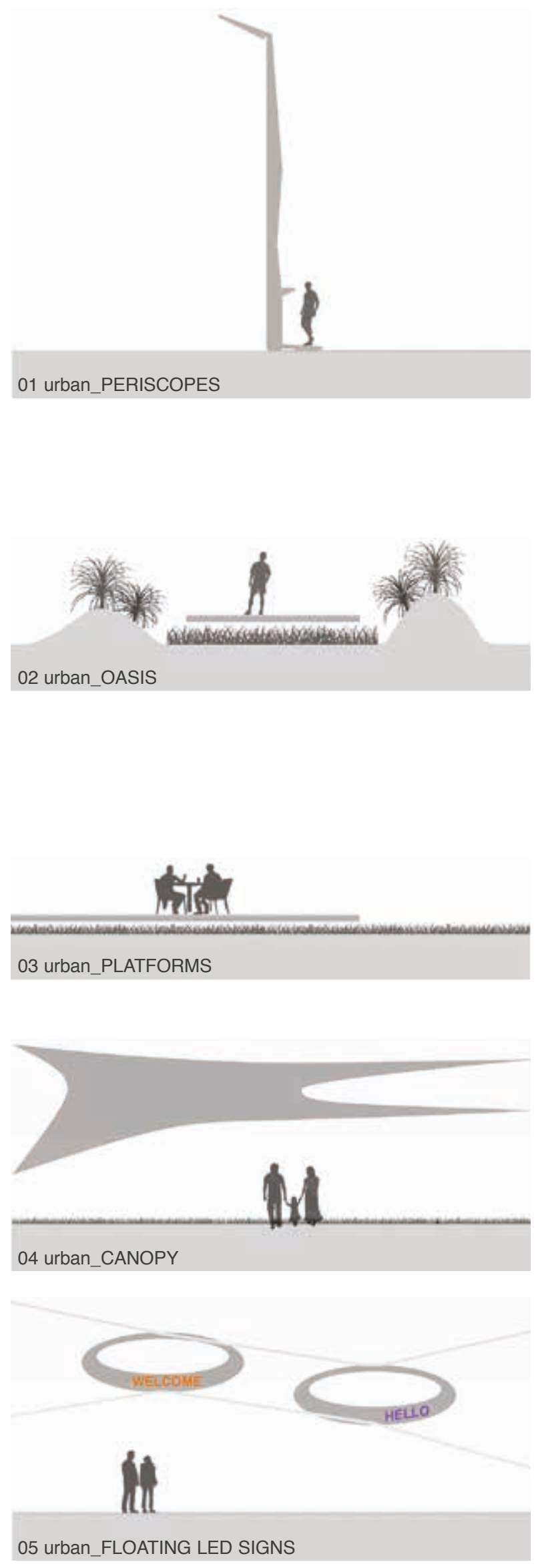

Figure 1. Diagrams of urban landscape elements (I).

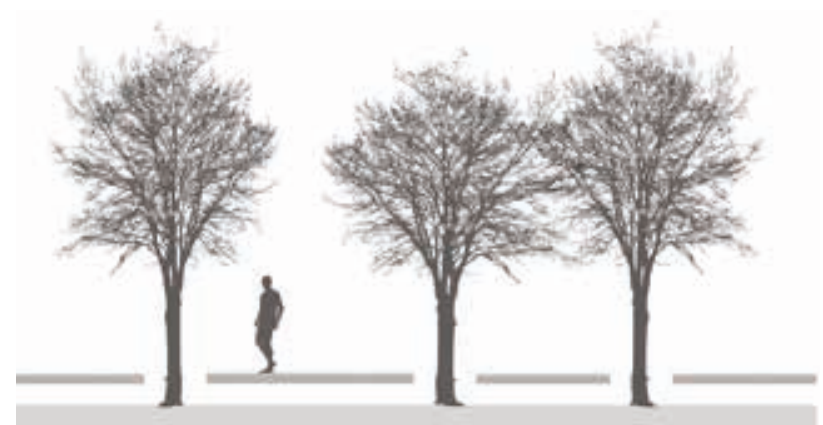

06 urban_TREE WELLS/FOREST
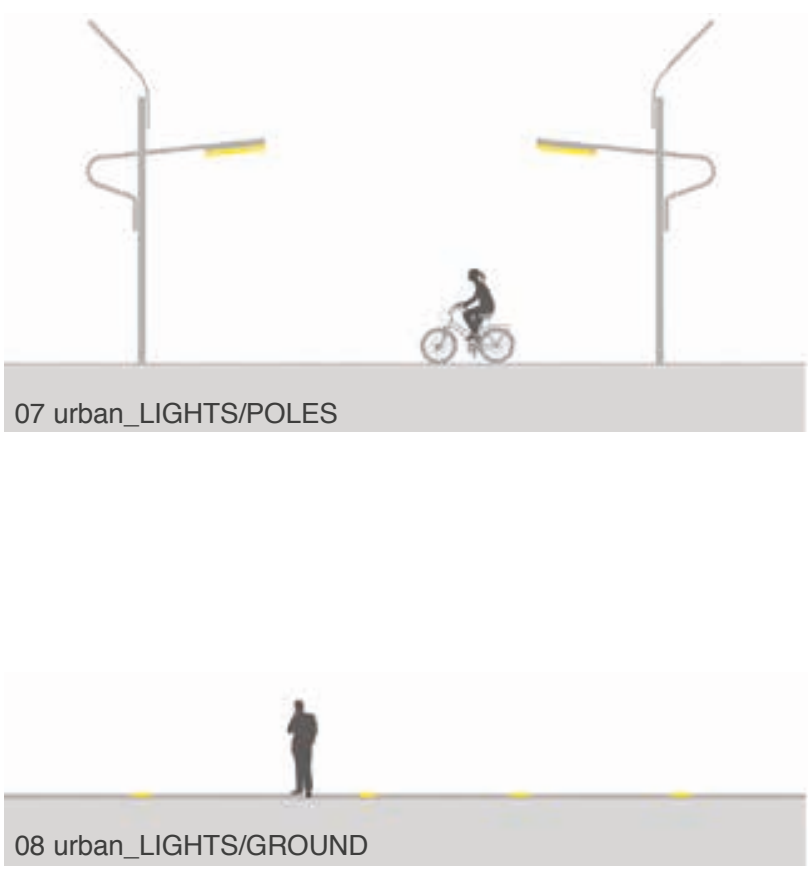

08 urban_LIGHTS/GROUND

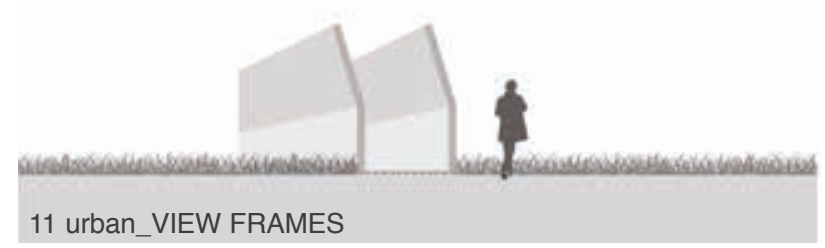



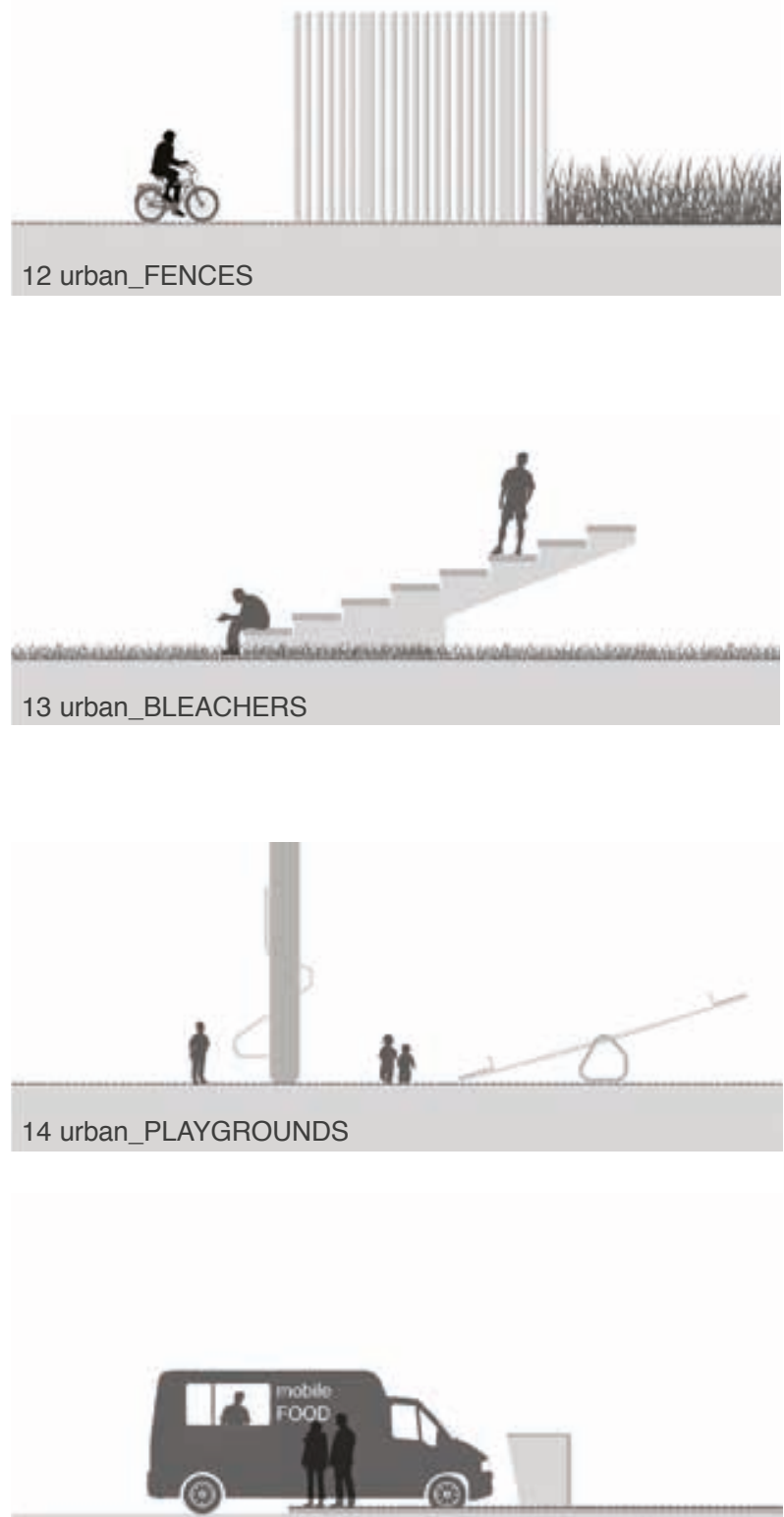

15 urban_MOBILE FOODS

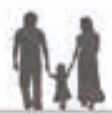

16 urban_LITTER BINS

Figure 2. Diagrams of urban landscape elements (II).

\section{बrosto}

17 urban_BIKE RACKS

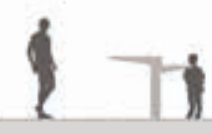

18 urban_DRINKING FOUNTAINS
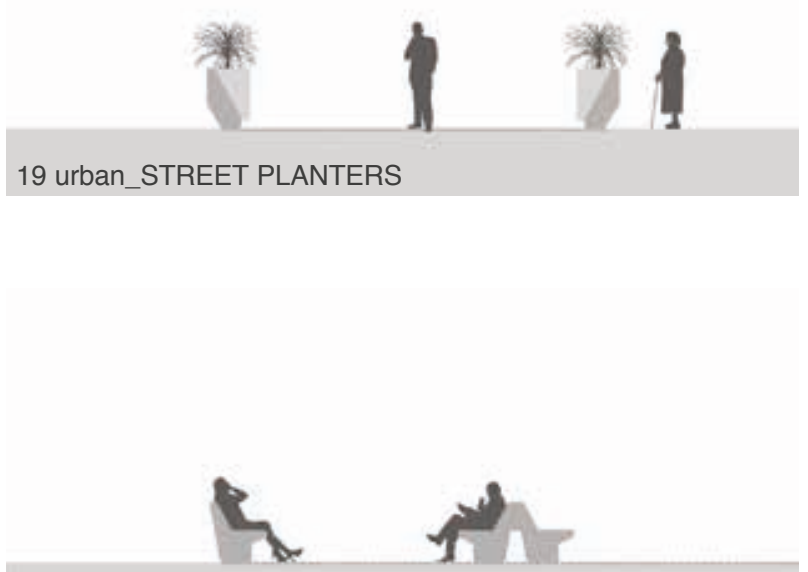

20 urban_STREET BENCHES

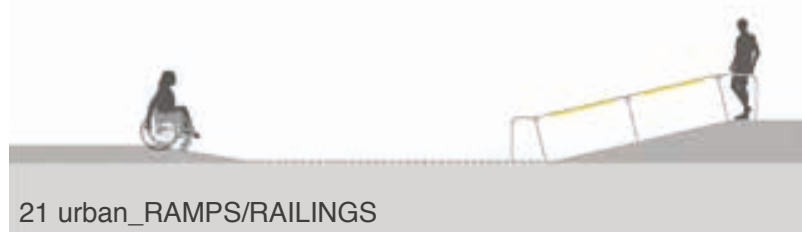




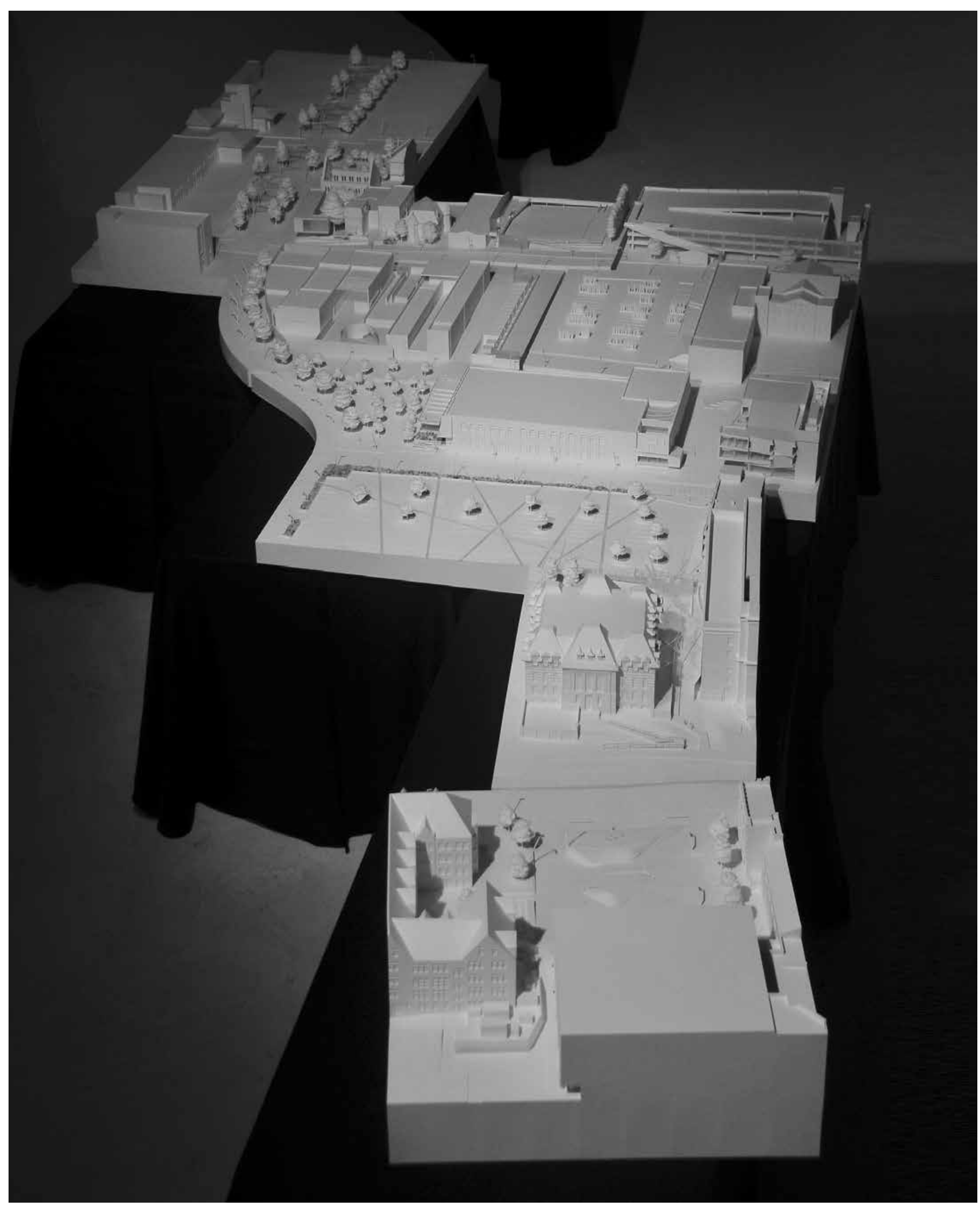

Figure 3. Site model, 3/32":1" (1:128) scale, 8'x20' (2.4x6 mt) overall dimension. 
01. SLU Knuckle

02. SLU Plaza

03. Lindell Sound Room

04. SLUMA Passage

05. SLUMA Garden

06. SLUMA Observation Deck

07. KETC Parking Lot

08. KETC Knuckle

09. Washington Knuckle

10. PXSTL

11. Pulitzer Entry

12. Pulitzer Floating Garden

13. Pulitzer Gate

14. Pulitzer Gate

15. CAM Entry

16. Spring Promenade
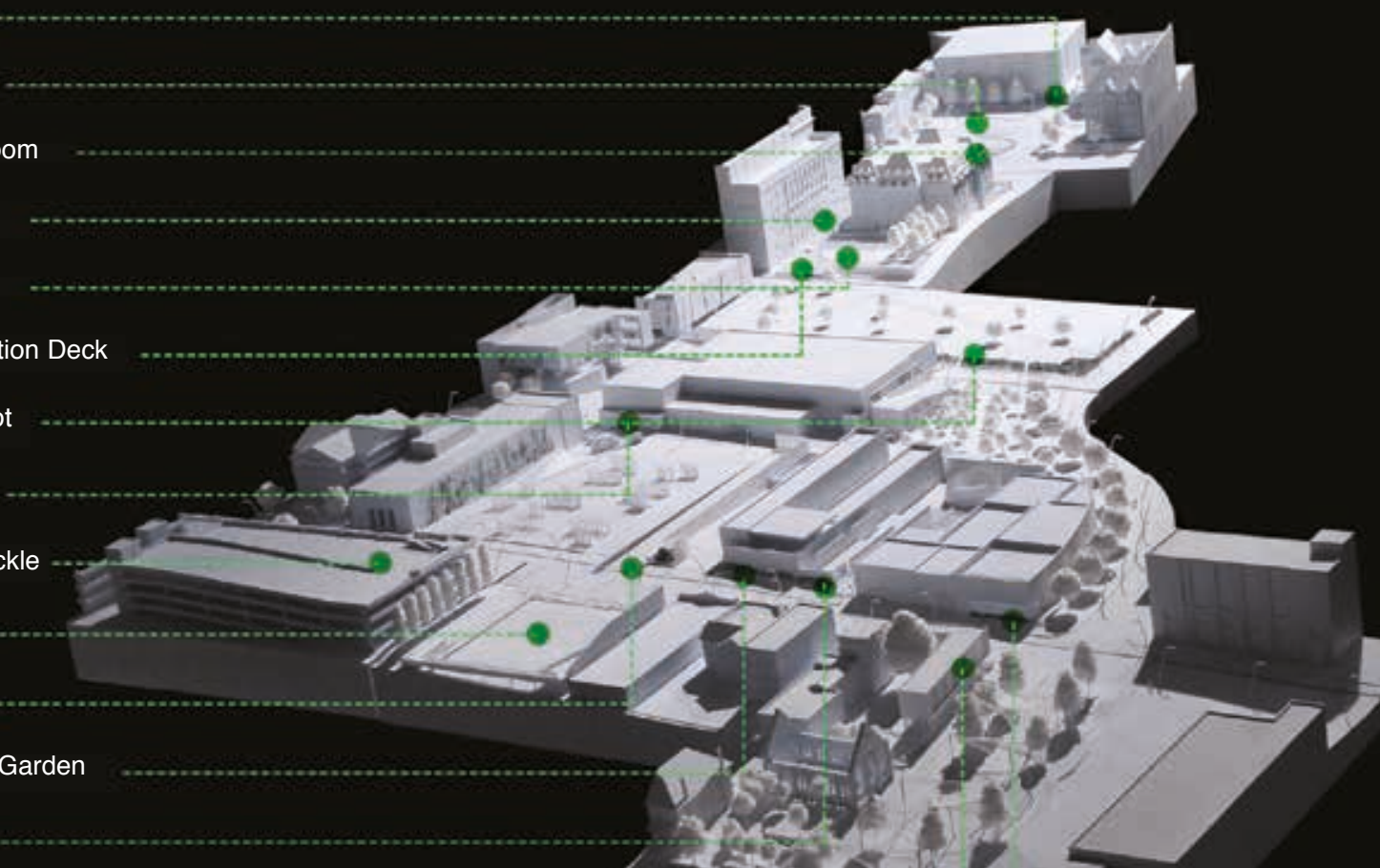


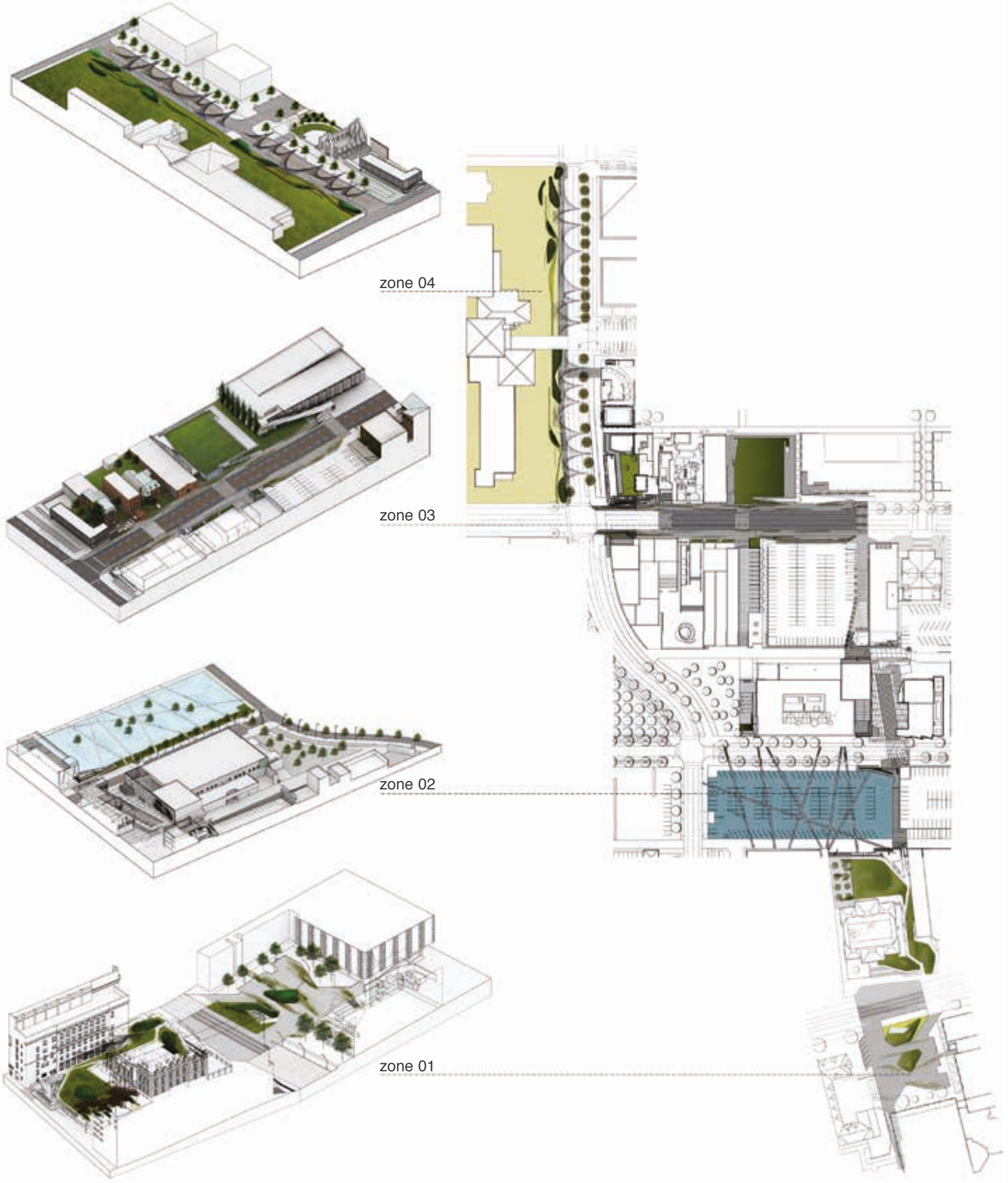

Figure 5. Site plan with the four zones. 


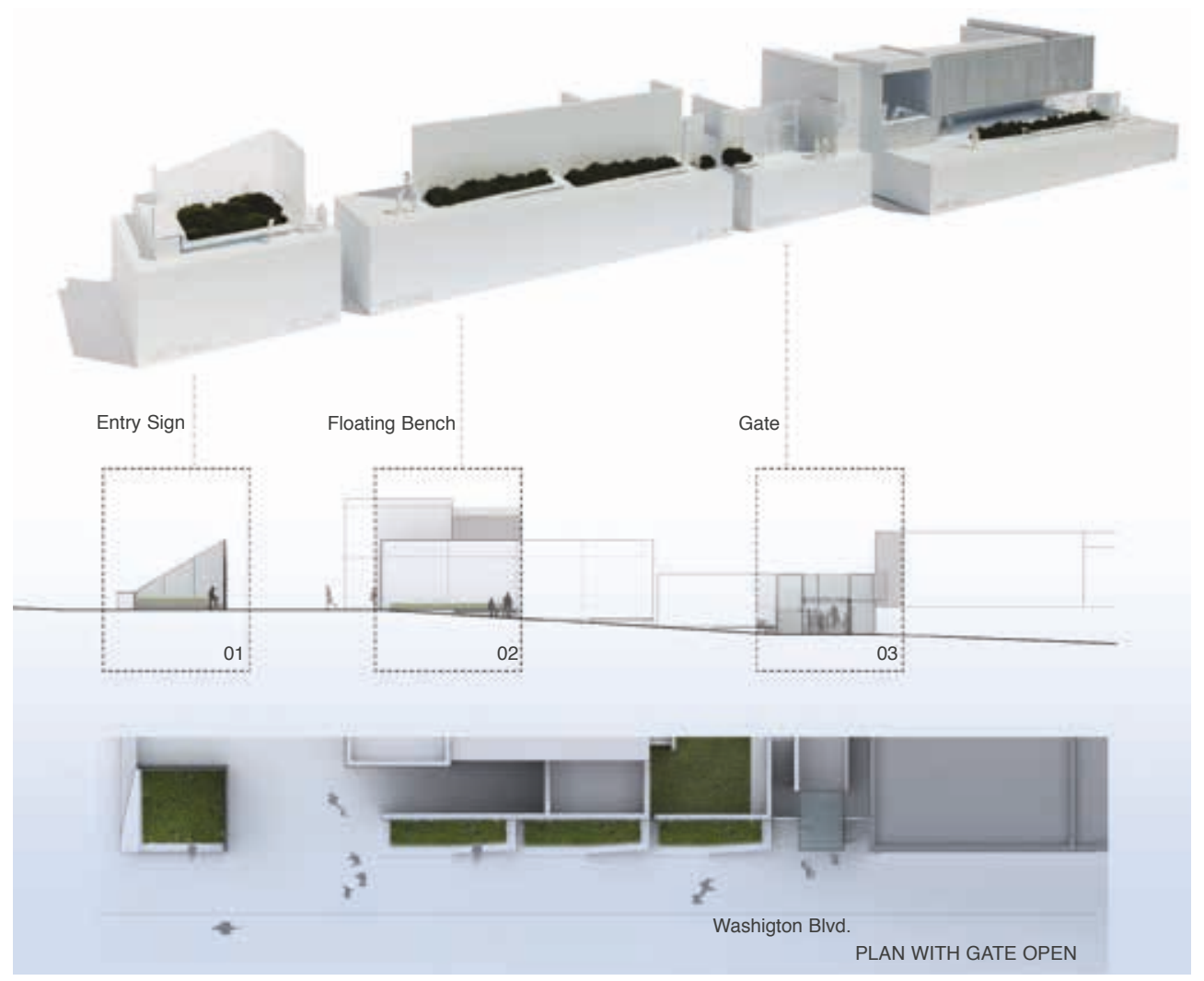

Figure 6. Detail model, $1 / 4 ": 1 "$ (1:48) scale, and drawing of entry condition at Pulitzer Arts Foundation and Contempoary Art Museum.

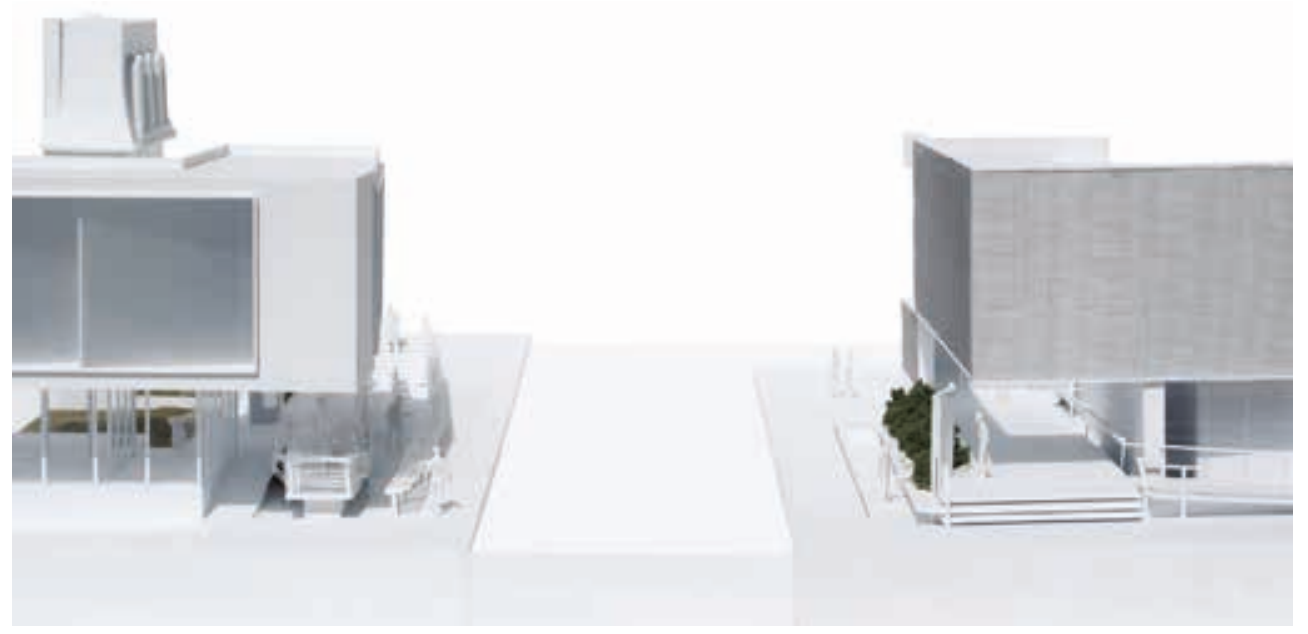

Figure 7. Detail model, 1/4":1" (1:48) scale, of Olive Street entry at Pulitzer Arts Foundation and Contempoary Art Museum 

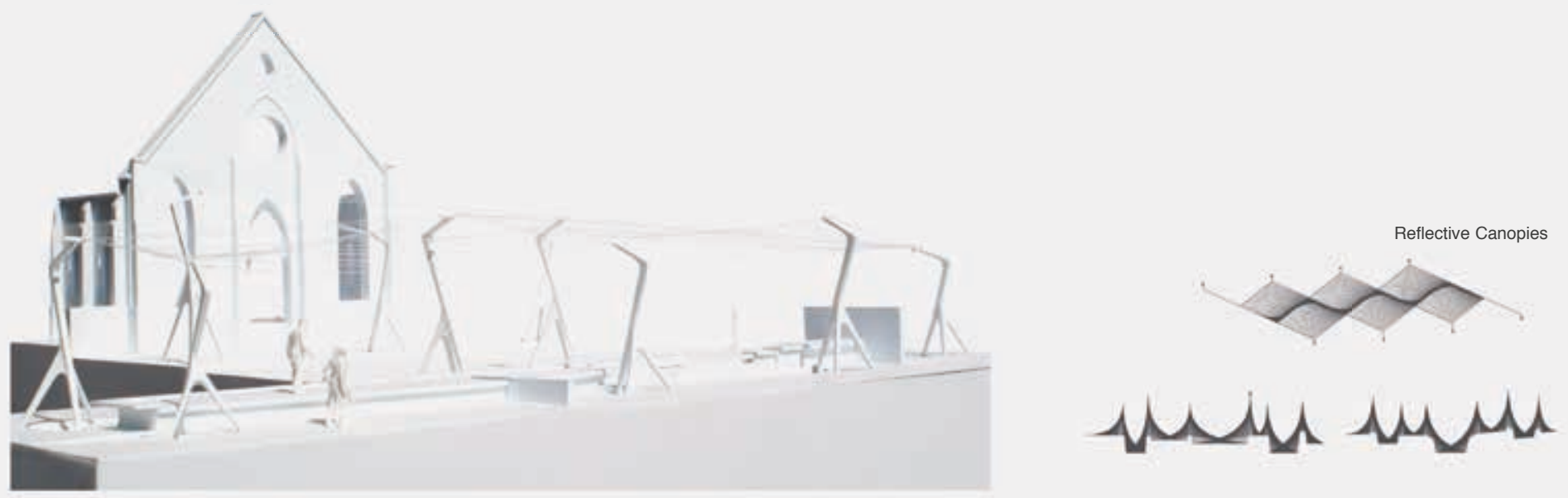

Figure 8. Detail model, 1/4":1" (1:48) scale, and diagram of reflective canopies.
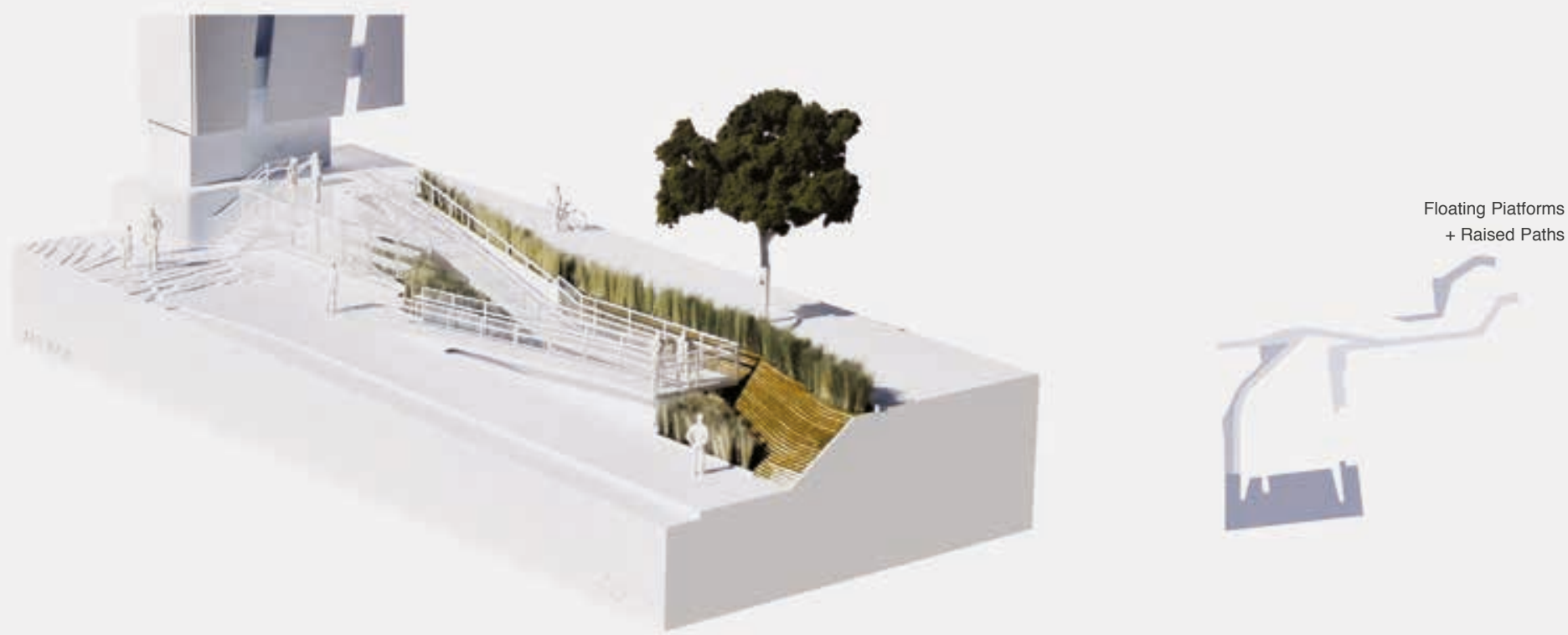

Figure 9. Detail model, $1 / 4 ": 1 "$ (1:48) scale, and diagram of floating platforms and raised paths.
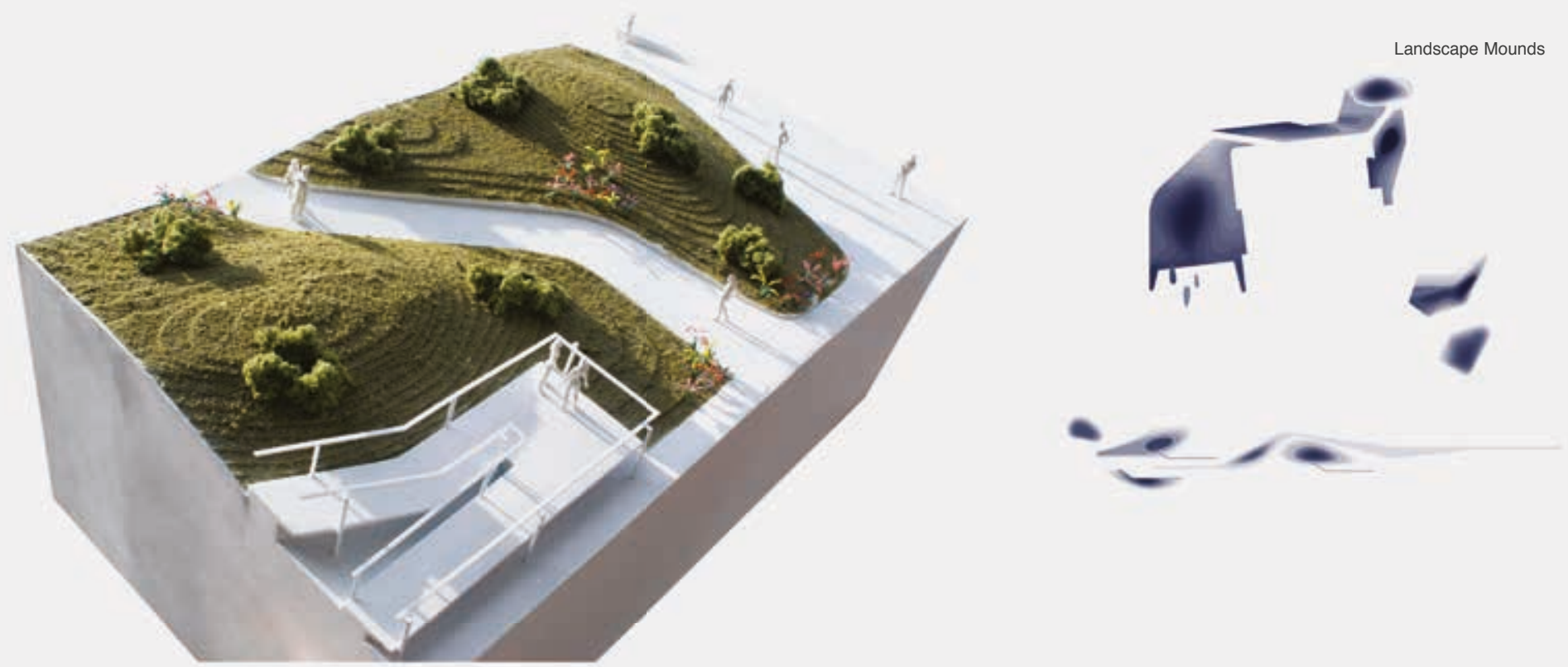

Figure 10. Detail model, 1/4":1" (1:48) scale, and diagram of landscape topography. 


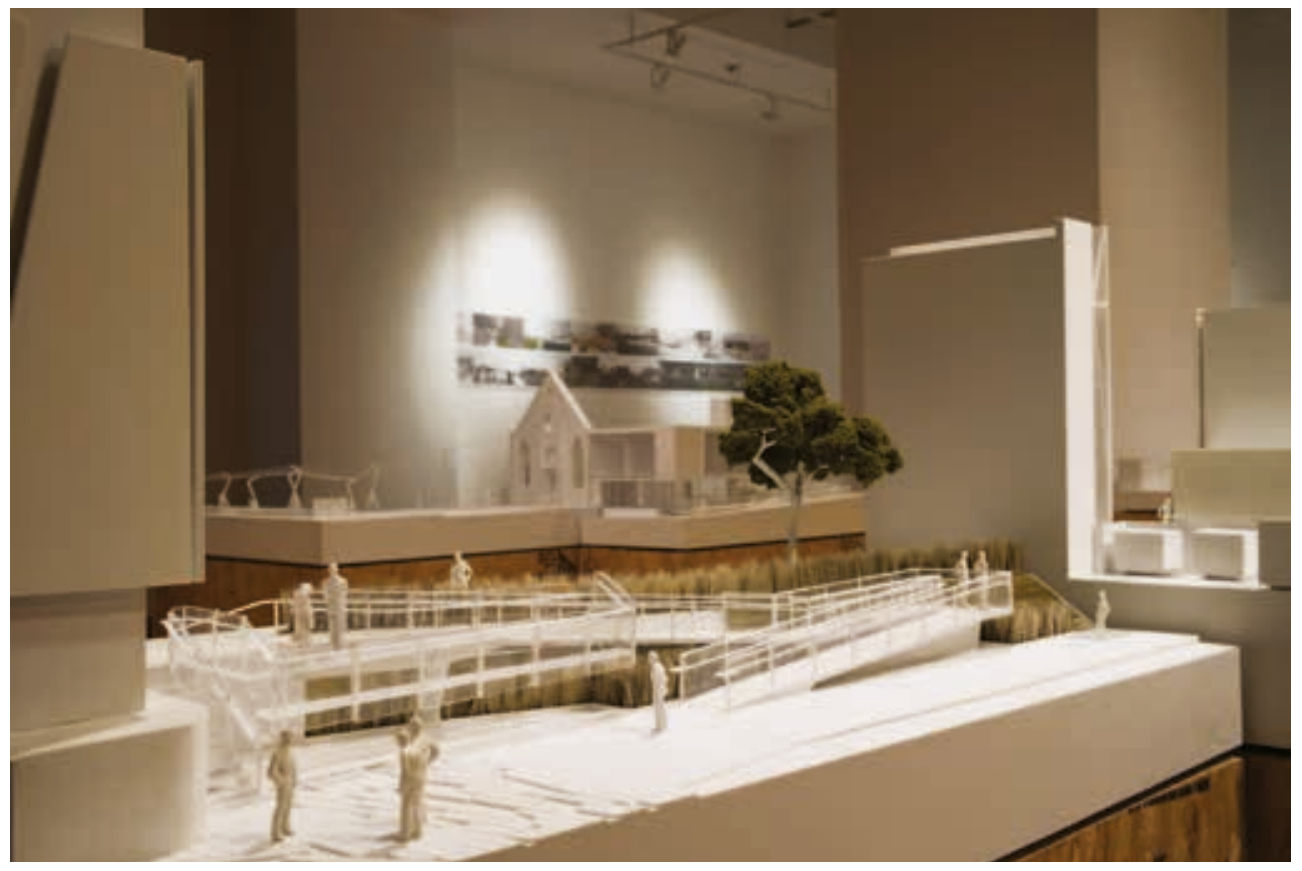

Figure 11. Detail model, 1/4":1" (1:48) scale, of floating platforms and raised paths.

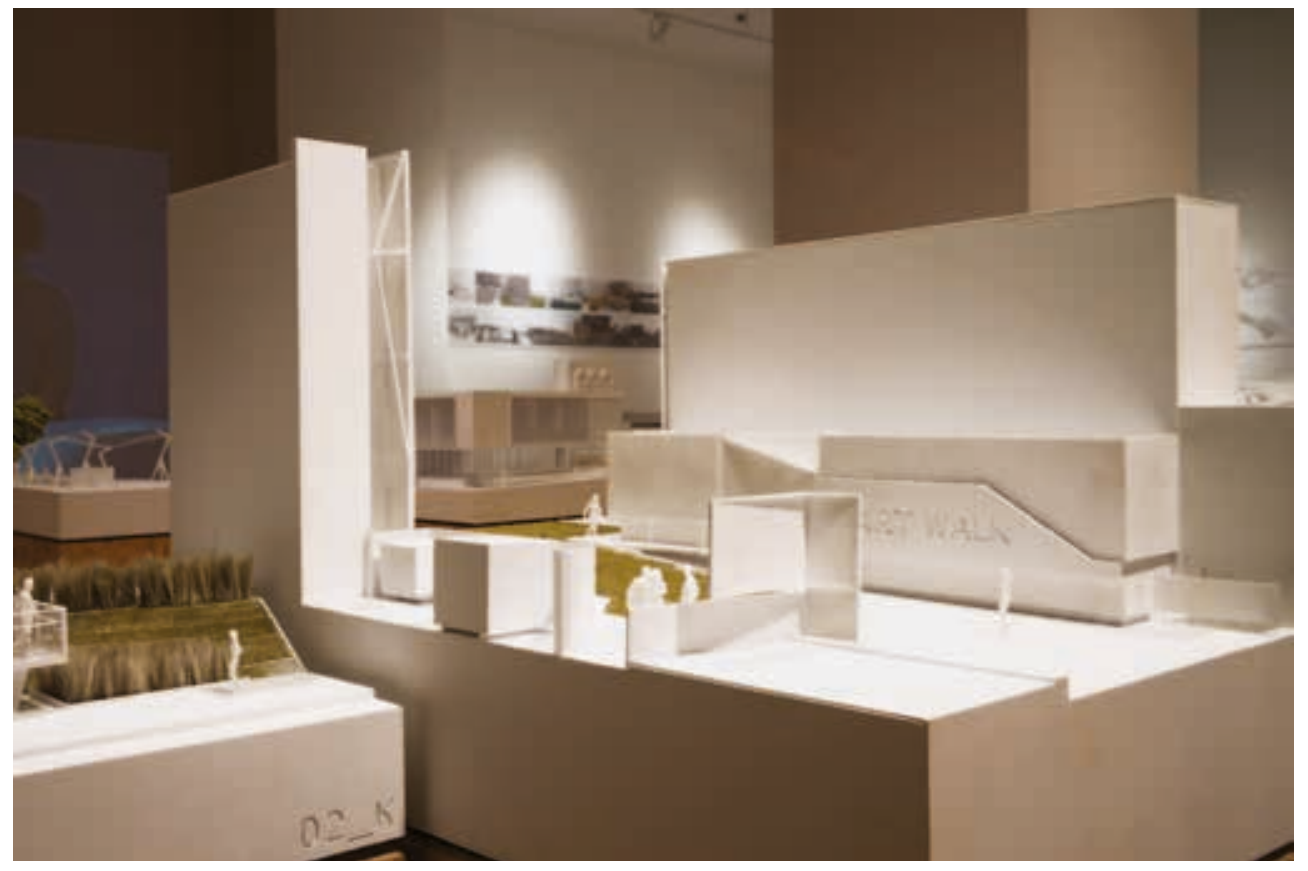

Figure 12. Detail model, 1/4":1" (1:48) scale, of Sheldon Art Museum and Nine Network knuckle connection. 

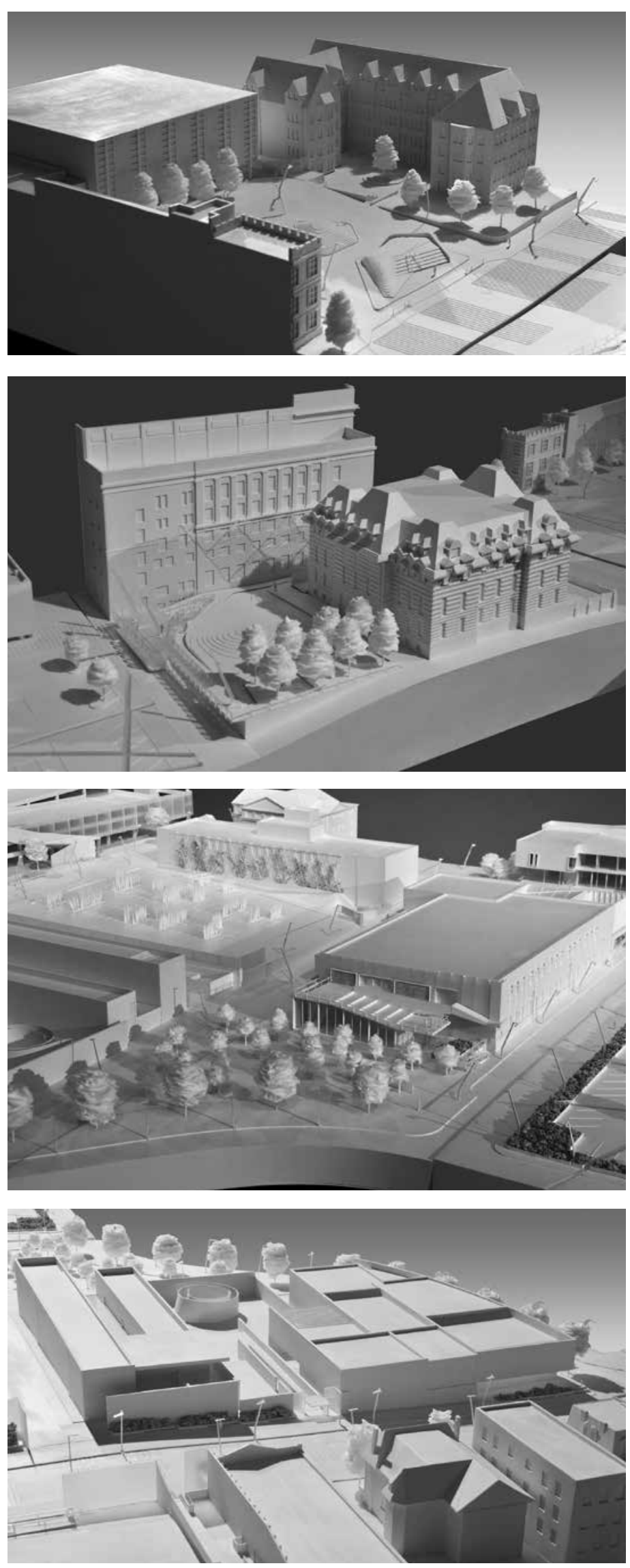

Figure 13.

St. Louis University

(SLU) zone.

Figure 14.

SLU Museum of Art and Scottish Rite zone.

Figure 15. Nine Network public television zone.

Figure 16.

Contemporary Art Museum, Pulitzer Arts Foundation zone. 


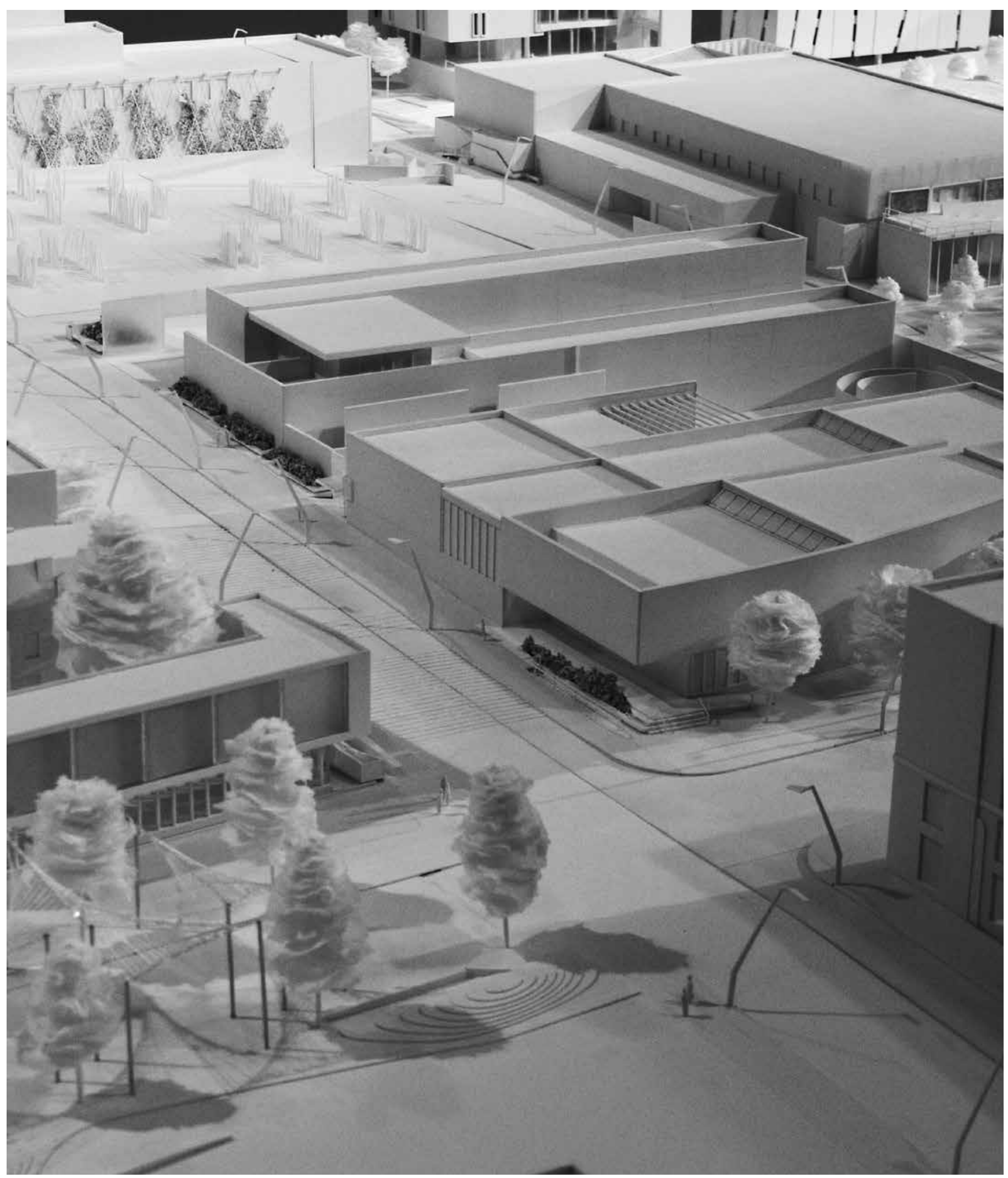

Figure 17. Contemporary Art Museum, Pulitzer Arts Foundation and reflective canopy zone. 
This project has been previously published, with a different selection of illustrations and an abridged text, in: Woofter, Heather, and Sung Ho Kim. Axi:Ome Ilc. Seoul: 3C Publishing Co., 2016.

\section{Project Team}

Architect: Axi:Ome Ilc - http://www.axi-ome.net/

Principals in Charge: Heather Woofter and Sung Ho Kim

Design Principal: Catty Dan Zhang

Project Manager and Coordinator: Jaymon Diaz

Project Designers: Evan Barrett and Elisa Kim

Design Team: Uros Stanojevic, Xuanchen Zhang, Zhengyang Wang, Young II Pyun,

Hannah Novack, David Poeyamidjaya, Chenglong Zhao, Haosheng Yu, Alex Kim and

Anthony Haun

Landscape Design Consultant: Irene Compadre

Landscape Technical Consultant: Rich Kacenski of DTLS Landscape Architects

Cost Estimating: Cooper Construction

Heather Woofter is a Registered Architect and passed Royal Institute of British Architects Parts I and II. She was an Assistant Professor at Virginia Polytechnic Institute, Visiting Professor at Aristotle University of Thessaloniki in Greece and Konkuk University in Seoul, Korea. Currently, she is a tenured Professor of Architecture and a Chair of the Graduate School of Architecture at Washington University in St. Louis. E-mail: woofter@wustl.edu Sung Ho Kim has Royal Institute of British Architects Parts I and II and Sung Ho taught at Rhode Island School of Design and was an Assistant Professor at Northeastern University. He was a Visiting Professor at Aristotle University of Thessaloniki in Greece and Konkuk University in Seoul, Korea. Currently, he is a tenured Associate Professor of Architecture and Graduate Core Coordinator at Washington University in St. Louis. E-mail: sungho@wustl.edu Heather and Sung Ho are founding directors of Axi:Ome llc of St. Louis (USA) since 2003. 